\title{
Complete genome of the cellulolytic thermophile Acidothermus cellulolyticus 11B provides insights into its ecophysiological and evolutionary adaptations
}

\author{
Ravi D. Barabote, ${ }^{1,9}$ Gary Xie, ${ }^{1}$ David H. Leu, ${ }^{2}$ Philippe Normand, ${ }^{3}$ Anamaria Necsulea, ${ }^{4}$ \\ Vincent Daubin, ${ }^{4}$ Claudine Médigue, ${ }^{5}$ William S. Adney, ${ }^{6}$ Xin Clare $\mathrm{Xu},{ }^{2}$ Alla Lapidus, ${ }^{7}$ \\ Rebecca E. Parales, ${ }^{8}$ Chris Detter, ${ }^{1}$ Petar Pujic, ${ }^{3}$ David Bruce, ${ }^{1}$ Celine Lavire, ${ }^{3}$ \\ Jean F. Challacombe, ${ }^{1}$ Thomas S. Brettin, ${ }^{1}$ and Alison M. Berry ${ }^{2,10}$ \\ ${ }^{1}$ DOE Joint Genome Institute, Bioscience Division, Los Alamos National Laboratory, Los Alamos, New Mexico 87545, USA; \\ ${ }^{2}$ Department of Plant Sciences, University of California, Davis, California 95616, USA; ${ }^{3}$ Centre National de la Recherche Scientifique \\ (CNRS), UMR5557, Écologie Microbienne, Université Lyon I, Villeurbanne F-69622, France; ${ }^{4}$ Centre National de la Recherche \\ Scientifique (CNRS), UMR5558, Laboratoire de Biométrie et Biologie Évolutive, Université Lyon I, Villeurbanne F-69622, France; \\ ${ }^{5}$ Centre National de la Recherche Scientifique (CNRS), UMR8030 and CEA/DSV/IG/Genoscope, Laboratoire de Génomique \\ Comparative, 91057 Evry Cedex, France; ${ }^{6}$ National Renewable Energy Laboratory, Golden, Colorado 80401, USA; ${ }^{7}$ DOE Joint \\ Genome Institute, Walnut Creek, California 94598, USA; ${ }^{8}$ Department of Microbiology, University of California, Davis, California \\ 95616, USA
}

\begin{abstract}
We present here the complete 2.4-Mb genome of the cellulolytic actinobacterial thermophile Acidothermus cellulolyticus 11B. New secreted glycoside hydrolases and carbohydrate esterases were identified in the genome, revealing a diverse biomassdegrading enzyme repertoire far greater than previously characterized and elevating the industrial value of this organism. A sizable fraction of these hydrolytic enzymes break down plant cell walls, and the remaining either degrade components in fungal cell walls or metabolize storage carbohydrates such as glycogen and trehalose, implicating the relative importance of these different carbon sources. Several of the A. cellulolyticus secreted cellulolytic and xylanolytic enzymes are fused to multiple tandemly arranged carbohydrate binding modules (CBM), from families 2 and 3 . For the most part, thermophilic patterns in the genome and proteome of $A$. cellulolyticus were weak, which may be reflective of the recent evolutionary history of $A$. cellulolyticus since its divergence from its closest phylogenetic neighbor Frankia, a mesophilic plant endosymbiont and soil dweller. However, ribosomal proteins and noncoding RNAs (rRNA and tRNAs) in A. cellulolyticus showed thermophilic traits suggesting the importance of adaptation of cellular translational machinery to environmental temperature. Elevated occurrence of IVYWREL amino acids in A. cellulolyticus orthologs compared to mesophiles and inverse preferences for $G$ and $A$ at the first and third codon positions also point to its ongoing thermoadaptation. Additional interesting features in the genome of this cellulolytic, hot-springs-dwelling prokaryote include a low occurrence of pseudogenes or mobile genetic elements, an unexpected complement of flagellar genes, and the presence of three laterally acquired genomic islands of likely ecophysiological value.
\end{abstract}

[Supplemental material is available online at www.genome.org. The complete genome of Acidothermus cellulolyticus 11B (ATCC 43068) has been deposited in GenBank (http://www.ncbi.nlm.nih.gov/Genbank/) under accession no. NC_008578.]

Efforts are under way worldwide to develop renewable energy sources as alternatives to fossil fuels. Microorganisms capable of breaking down lignocellulosic plant matter, a bioenergy source, are of enormous interest in the global quest to identify enzymes that can convert biomass into biofuels. Acidothermus cellulolyticus was first isolated in enrichment cultures from acidic hot springs in Yellowstone National Park, in a screen for microorganisms that carry out efficient cellulose degradation at high temperature (Mohagheghi et al. 1986). A. cellulolyticus 11B is acid-tolerant (pH

\footnotetext{
9Present address: Department of Plant Sciences, University of California, Davis, CA 95616, USA.

Article published online before print. Article and publication date are at http://www.genome.org/cgi/doi/10.1101/gr.084848.108.
}

4-6, with optimal pH 5.5) and thermophilic (growth between $37^{\circ} \mathrm{C}$ and $70^{\circ} \mathrm{C}$; the optimal growth temperature [OGT] is $55^{\circ} \mathrm{C}$ ). It produces many thermostable cellulose-degrading enzymes (Tucker et al. 1989; Baker et al. 1994; Adney et al. 1995; Ding et al. 2003). One of the endoglucanases, E1, which has been crystallized, is highly thermostable to $81^{\circ} \mathrm{C}$ and has very high specific activity on carboxymethylcellulose (Thomas et al. 1995; Sakon et al. 1996). E1 has been expressed in several plants and shows promise for generating genetically improved feedstock for the production of affordable cellulosic ethanol (Sticklen 2008). Hydrolytic enzymes from $A$. cellulolyticus have great potential in the biofuels industry because of their thermostability and activity at low pH (Rubin 2008).

A. cellulolyticus is a member of the Frankineae, a high $\mathrm{G}+\mathrm{C}$, primarily Gram-positive Actinobacterial group (Rainey 
and Stackebrandt 1993). All of the characterized strains of $A$. cellulolyticus are thermophilic and do not grow below $37^{\circ} \mathrm{C}$ (Mohagheghi et al. 1986). This makes the evolutionary context of A. cellulolyticus interesting, because its closest known phylogenetic neighbor is the mesophilic actinobacterium Frankia, based on the analysis of the 16S rRNA, recA, and shc nucleotide sequences (Supplemental Fig. S1; Normand et al. 1996; Marechal et al. 2000; Alloisio et al. 2005). Frankia is a mesophilic (OGT $25^{\circ} \mathrm{C}-28^{\circ} \mathrm{C}$ ), nitrogen-fixing soil organism that forms symbiotic root nodule associations with plants (Benson 1988). The genetic distance between A. cellulolyticus and three Frankia strains-ACN14a, CcI3, and EAN1pec-is very small and comparable to that found between certain strains within the Frankia species. Thus, although Acidothermus and Frankia share a close phylogenetic relationship at the DNA sequence level, they have evolved to live in dramatically diverse environments over the last 200-250 million years (Myr) since their last common ancestor (Normand et al. 2007). Complete genome sequences of three Frankia strains-ACN14a, $\mathrm{CcI} 3$, and EAN1pec-as well as those of other close relatives of A. cellulolyticus are now available, including the mesophilic Streptomyces avermitilis, Streptomyces coelicolor, and the terrestrial thermophilic Thermobifida fusca (Omura et al. 2001; Bentley et al. 2002; Ikeda et al. 2003; Lykidis et al. 2007; Normand et al. 2007). Genomic comparison of $A$. cellulolyticus with the mesophilic as well as thermophilic actinobacteria could provide insight into the nature of adaptation of this aquatic thermophile and add to our understanding of evolution within the actinobacteria.

We present analysis of the complete genome of Acidothermus cellulolyticus 11B (ATCC 43068; GenBank accession NC_008578). Insights into the biomass degradation capabilities of the organism as well as thermophilic features of its genome and proteome are discussed. In addition, we discuss three laterally acquired genomic islands with genes of likely ecophysiological value, as well as the unexpected presence of flagellar genes in the genome.

\section{Results}

\section{General genome characteristics}

The 2.44-Mb genome of $A$. cellulolyticus is encoded on a single circular chromosome (Fig. 1) and is $\sim 66.9 \% \mathrm{G}+\mathrm{C}$ rich. The $\mathrm{G}+\mathrm{C}$ content of the noncoding region $(68.41 \%)$ is higher than the $\mathrm{G}+\mathrm{C}$ content of the coding region $(66.76 \%)$. The total GC-skew analysis revealed a potential origin of replication (OriC) upstream of the $d n a A$ gene and a terminus at $\sim 1.2 \mathrm{Mb}$ from the origin. A single $r r n$ operon containing the genes for the 16S, 23S, and 5S rRNAs is located toward the replication terminus, an unusual position. Forty-five tRNAs representing 43 different anticodons are encoded in the genome (Supplemental Table S1; Supplemental Material). The $A$. cellulolyticus genome contains only four annotated pseudogenes (Acel_0124, Acel_0186, Acel_0477, Acel_1066) that do not encode any protein products. The protein-coding sequence constitutes $\sim 90 \%$ of the genome and encodes 2157 predicted proteins. No identifiable prophages or phage-related proteins were found in the genome, and only two genes encoding fragments of a single transposase (Acel_1666, Acel_1667) were found in the genome. One-fifth of all the predicted proteins have no decipherable function. Approximately $8 \%$ of the proteins (171 proteins) do not show sequence similarity to any sequences in the NCBI database and thus appear to be ORFans unique to $A$. cellulolyticus (Supplemental Fig. S2). Analysis of the phyletic distribution of BLAST hits of the remaining proteins revealed that

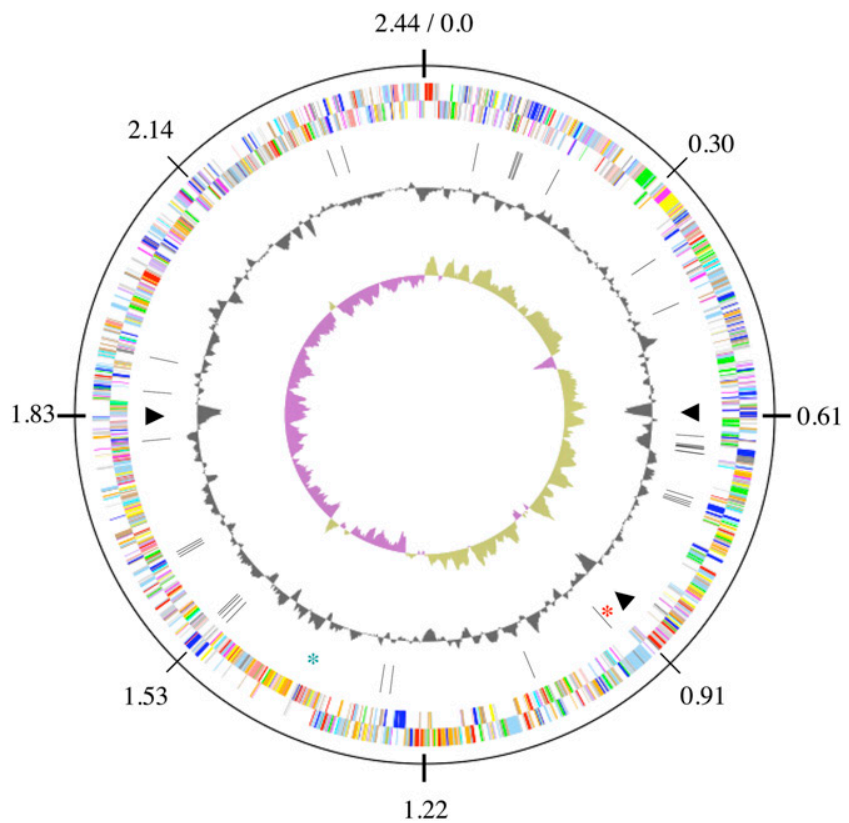

Figure 1. Schematic of the A. cellulolyticus 11B genome. The outermost circle gives the genome coordinates. The next two inner rings show the predicted genes on the leading (outer circle) and the lagging (inner circle) strands. Color scheme is as follows: dark gray, hypothetical proteins; light gray, conserved hypothetical and unknown function; brown, general function prediction; red, replication and repair; green, energy metabolism; blue, carbon and carbohydrate metabolism; cyan, lipid metabolism; magenta, transcription; yellow, translation; orange, amino acid metabolism; pink, metabolism of cofactors and vitamins; light red, purine and pyrimidine metabolism; lavender, signal transduction; sky blue, cellular processes; pale green, structural RNAs. Ring 4 displays the positions of the glycoside hydrolases (black bars), the three Gls (triangles), the flagellar biosynthetic genes (red star), and the rRNA operon (blue star). Ring 5 shows the $\mathrm{G}+\mathrm{C}$ content along the genome. The innermost ring, ring 6 , displays the GC skew.

$\sim 80 \%$ of the A. cellulolyticus proteins show highest sequence similarity to proteins from other actinobacteria (Supplemental Fig. S2). Within the actinobacterial hits, the highest number of best BLAST hits, surprisingly, were to the phylogenetically more remote Streptomyces spp. $(\sim 18 \%)$, more so than to its closest phylogenetic neighbor Frankia spp. ( 17\%), and followed by $T$. fusca ( $\sim 13 \%)$. Interestingly, 18 A. cellulolyticus proteins bear highest sequence similarity to archaeal proteins, and seven proteins show highest sequence similarity to eukaryotic proteins (Supplemental Table S2).

Based on the distribution of the top BLAST hits to Frankia, Streptomyces, and T. fusca, sequenced genomes of these organisms were used for comparative genome analyses. An overview of the $A$. cellulolyticus genome features in comparison with the genomes of Frankia, Streptomyces, and T. fusca is provided in Table 1.

\section{Carbohydrate active enzymes}

The genome of $A$. cellulolyticus contains at least 43 genes encoding 35 glycoside hydrolase $(\mathrm{GH})$ and eight carbohydrate esterase (CE) enzymes (Table 2). Of these, 28 predicted enzymes break down structural or storage carbohydrates found in plant and fungal cells, including cellulose, xylan, starch, and chitin. The GHs belong to 17 families, while the CEs span five families as per the CAZy database (Henrissat 1991; Coutinho and Henrissat 1999) 
Table 1. Comparative features of Acidothermus cellulolyticus 11B and close actinobacterial relatives ${ }^{\mathrm{a}}$

\begin{tabular}{|c|c|c|c|c|c|c|}
\hline Features & $\begin{array}{c}\text { Acidothermus cellulolyticus } \\
\text { 11B }\end{array}$ & $\begin{array}{l}\text { Frankia sp. } \\
\mathrm{Ccl} 3\end{array}$ & $\begin{array}{l}\text { Frankia alni } \\
\text { ACN14a }\end{array}$ & $\begin{array}{c}\text { Streptomyces avermitilis } \\
\text { MA-4680 }\end{array}$ & $\begin{array}{c}\text { Streptomyces coelicolor } \\
\mathrm{A3}(2)\end{array}$ & $\begin{array}{c}\text { Thermobifida fusca } \\
\text { YX }\end{array}$ \\
\hline OGT & $55^{\circ} \mathrm{C}$ & $27^{\circ} \mathrm{C}$ & $28^{\circ} \mathrm{C}$ & $28^{\circ} \mathrm{C}$ & $30^{\circ} \mathrm{C}$ & $50^{\circ} \mathrm{C}$ \\
\hline Genome size (Mb) & 2.4 & 5.4 & 7.5 & 9.0 & 8.7 & 3.6 \\
\hline $\mathrm{G}+\mathrm{C}$ of the genome & $66.9 \%$ & $70.1 \%$ & $72.8 \%$ & $70.7 \%$ & $72.1 \%$ & $67.5 \%$ \\
\hline Coding DNA fraction & $89 \%$ & $84 \%$ & $86 \%$ & $86 \%$ & $88 \%$ & $85 \%$ \\
\hline Predicted proteins & 2157 & 4499 & 6711 & 7577 & 7769 & 3110 \\
\hline rRNA operons & 1 & 2 & 2 & 6 & 5 & 4 \\
\hline tRNA genes & 46 & 46 & 46 & 68 & 64 & 52 \\
\hline Pseudogenes & 4 & 50 & 12 & 0 & 56 & 7 \\
\hline Transposase/IS elements & $2^{b}$ & 145 & 33 & 110 & 55 & 5 \\
\hline Phage/viral proteins & 0 & 6 & 24 & 20 & 8 & 3 \\
\hline
\end{tabular}

${ }^{a}$ The genomes chosen for comparison were based on two attributes: (1) The majority of the top BLAST hits of $A$. cellulolyticus proteins were from these species (see Supplemental Fig. S2); and (2) both mesophilic and thermotolerant species were represented.

${ }^{\mathrm{b}}$ The two transposase genes are frame-shifted fragments of an intact gene found in Frankia and thus are unlikely to encode a functional transposase in $A$. cellulolyticus.

(http://www.cazy.org/). At least 15 GHs belonging to families 1, 3, $5,6,9,10,12,16,48$, and 74; and three CEs from families 1 and 7 may be important for plant biomass deconstruction in A. cellulolyticus. Two or more representatives of several of these enzyme families occur in the genome, except for GH1, 16, 48, and 74 and CE7 (Table 2).

Five previously described carbohydrate active enzymes (Ding et al. 2003) could be correctly mapped in the genome (Table 2). While these known cellulolytic enzymes are encoded in a large gene cluster (Ding et al. 2003), genes encoding many newly identified enzymes occur scattered throughout the genome (Fig. 1). The genome revealed six new cellulose-degrading enzymes including four endoglucanases and two beta-glucosidases. In addition, six enzymes for hemicellulose decomposition were identified including two xylanases, three xylan esterases, and a xylosidase. Except for the GH1 beta-glucosidase and the GH3 xylosidase that are predicted to be cytoplasmic as well as the CE7 esterase, the rest of the plant cell-wall-degrading enzymes are either predicted to be secreted or contain a signal peptide (Table 2).

In addition to the 17 plant cell-wall-degrading enzymes, the genome encodes 10 proteins potentially associated with the breakdown of fungal cell wall components. Two beta$\mathrm{N}$-acetylhexosaminidases and a chitooligosaccharide deacetylase were predicted to be cytoplasmic, while the other seven proteins are either predicted to be secreted or have a signal sequence indicating that they are likely to be secreted. These include four chitinases, an $\mathrm{N}$-acetylglucosaminidase, a GH16 endo-1,3beta-glucanase, and a CenC-domain-containing putative chitinbinding protein.

Sixteen enzymes are involved in either glycogen and trehalose biosynthesis and degradation (eight enzymes) or related cellular metabolic functions (Table 2). The GH13 alpha amylase (Acel_0679) may additionally participate in starch metabolism. None of these enzymes contains a signal sequence and is predicted to be cytoplasmic except the two GH23 lytic transglycosylases that may be cell-wall associated.

\section{Carbohydrate-binding modules (CBMs)}

Catalytic domains of two-thirds of the 21 secreted biomassdegrading enzymes in A. cellulolyticus were found fused to one or more CBM types (Table 2). Furthermore, members of the same GH families carry varying numbers and combinations of fused CBMs. Only one of the esterases (CE1) was fused to CBMs. The cellulose- and xylan-degrading A. cellulolyticus enzymes contain C-terminally fused CBM2 domains, a feature that was found to be similar to other actinobacterial homologs. However, many $A$. cellulolyticus enzymes additionally contain CBM3 domains. Curiously, CBM3 was always found to occur N-terminal relative to CBM2, but never C-terminal to it. In general, the two CBM types were found to occur in tandem (as X-CBM3-CBM2, where $\mathrm{X}$ is $\mathrm{GH}, \mathrm{CE}$, or CBM3 domain), except in the case of the Gux1 exoglucanase and the GuxA cellulase where the two CBMs are separated by a $\mathrm{GH}$ domain (CBM3-X-CBM2). Although two endoglucanases, the previously characterized endoglucanase E1 (GH5) and a newly identified GH12 endoglucanase, contain just the CBM2, no enzymes with only the CBM3 module occur in the genome.

Overall, the $A$. cellulolyticus genome encodes about equal numbers of the two CBM types-10 CBM2 and nine CBM3 modules. Comparative genome analysis revealed that Frankia alni ACN14a and CCI3 lack either CBMs, while a single CBM2 fused to a chitinase was found in Frankia sp. EAN1pec. However, the three Frankia genomes also lack cellulolytic enzymes. The genomes of two close actinobacterial relatives with multiple cellulolytic enzymes, Streptomyces and Thermobifida, contain 11-14 CBM2 modules but just one to two CBM3 modules. In contrast, the genome of the anaerobic cellulosome-forming bacterium Clostridium thermocellum encodes about 24 CBM3 domains but no CBM2 homologs. Analysis of each of the two CBM types revealed that the sequences are highly conserved in A. cellulolyticus. In contrast, the different CBM2 domains in Streptomyces or Thermobifida, or the several CBM3 domains in C. thermocellum, exhibit sequence diversity.

In addition to the two CBM families, a single copy of CBM6 was found attached to a GH16 endo-1,3-beta-glucanase. Three of the secreted chitinases also contained CBM5 and/or CBM16 domains. A few of the cytoplasmic enzymes involved in glycogen/ trehalose metabolism contain one to two CBM48 modules.

\section{Genomic islands}

Three major genomic islands (GIs) with significantly lower $\mathrm{G}+\mathrm{C}$ and deviant dinucleotide signature were identified (Fig. 2). Several proteins encoded in these islands have no recognizable orthologs in close relatives of $A$. cellulolyticus. GI1 consists of 15 genes with an average $\mathrm{G}+\mathrm{C}$ of $58 \%$ (Table 3 ). The first five genes likely 
Table 2. Carbohydrate active enzymes encoded in the A. cellulolyticus 11B genome

\begin{tabular}{|c|c|c|c|c|c|c|c|}
\hline Locus tag & $\mathrm{MW}^{\mathrm{a}}$ & Domains $^{b}$ & Known or predicted function & Role $^{c}$ & $\operatorname{Sig}^{d}$ & $\operatorname{Loc}^{\mathrm{e}}$ & Reference $^{f}$ \\
\hline Acel_0072 & 60 & $\mathrm{GH} 2 \mathrm{O}$ & Beta- $N$-acetylhexosaminidase (EC 3.2.1.52) & Fun & $\mathrm{Y}$ & Cyt & \\
\hline Acel_0128 & 50 & $\mathrm{GH} 3$ & Beta- $N$-acetylhexosaminidase & Fun & $\mathrm{N}$ & Cyt & \\
\hline Acel_0129 & 49 & GH16-CBM6 & Endo-1,3-beta-glucanase & Fun & $\mathrm{Y}$ & U & \\
\hline Acel_0133 & 53 & $\mathrm{GH} 1$ & Beta-glucosidase (EC3.2.1.21) & Cel & $\mathrm{N}$ & Cyt & \\
\hline Acel_0135 & 51 & $\mathrm{GH} 6$ & Beta-1,4-endoglucanase (CelB; EC 3.2.1.4) & Cel & $\mathrm{Y}$ & U & \\
\hline Acel_0179 & 68 & CE1-CBM3-CBM2 & Acetyl-xylan esterase & Hem & $\mathrm{Y}$ & $\mathrm{Sec}$ & \\
\hline Acel_0180 & 71 & GH10-CBM3-CBM2 & Beta-1,4-xylanase & Hem & $\mathrm{Y}$ & $\mathrm{Sec}$ & \\
\hline Acel_0372 & 43 & $\mathrm{GH} 10$ & Endo-1,4-beta-xylanase (EC 3.2.1.8) & Hem & Y & $\mathrm{Sec}$ & \\
\hline Acel_0374 & 27 & CE14 & Putative deacetylase & M & $\mathrm{N}$ & Cyt & \\
\hline Acel_0424 & 83 & $\mathrm{GH} 18$ & $\mathrm{~N}$-Acetylglucosaminidase & Fun & $\mathrm{Y}$ & $\mathrm{Sec}$ & \\
\hline Acel_0557 & 40 & CE9 & $\mathrm{N}$-Acetylglucosamine 6-phosphate deacetylase & M & $\mathrm{N}$ & Cyt & \\
\hline Acel_0603 & 51 & $\mathrm{GH} 18$ & Chitinase & Fun & $\mathrm{Y}$ & U & \\
\hline Acel_0614 & 61 & GH5-CBM2 & Endo-1,4-glucanase E1 (Cel5A; EC 3.2.1.4) & Cel & $\mathrm{Y}$ & $\mathrm{Sec}$ & 1,2 \\
\hline Acel_0615 & 125 & GH6-CBM3-GH12-CBM2 & Cellulase (GuxA;EC3.2.1.4) & Cel & $\mathrm{Y}$ & $\mathrm{Sec}$ & 2 \\
\hline Acel_0616 & 80 & GH5-CBM3-CBM2 & Mannanase (ManA) & Hem & $\mathrm{Y}$ & $\mathrm{Sec}$ & 2 \\
\hline Acel_0617 & 119 & CBM3-GH48-CBM2 & Exoglucanase (Gux1) & Cel & $\mathrm{Y}$ & $\mathrm{Sec}$ & 2 \\
\hline Acel_0618 & 134 & GH74-CBM3-CBM2 & Avicelase (Cel74A) & Cel & $\mathrm{Y}$ & $\mathrm{Sec}$ & 2 \\
\hline Acel_0619 & 41 & $\mathrm{GH} 12-\mathrm{CBM} 2$ & Endoglucanase & Cel & $\mathrm{Y}$ & $\mathrm{Sec}$ & \\
\hline Acel_0676 & 82 & CBM48-CBM48-GH13 & 1,4-Alpha-glucan branching enzyme & $\mathrm{G} / \mathrm{T}$ & $\mathrm{N}$ & Cyt & \\
\hline Acel_0678 & 65 & $\mathrm{GH} 13$ & Trehalose synthase & $\mathrm{G} / \mathrm{T}$ & $\mathrm{N}$ & Cyt & \\
\hline Acel_0679 & 73 & $\mathrm{GH} 13$ & Alpha amylase & $\mathrm{G} / \mathrm{T}$ & $\mathrm{N}$ & Cyt & \\
\hline Acel_0681 & 78 & CBM48-GH13 & Glycogen debranching enzyme GlgX & $\mathrm{G} / \mathrm{T}$ & $\mathrm{N}$ & Cyt & \\
\hline Acel_0767 & 41 & CE1 & Putative esterase & Hem & $\mathrm{Y}$ & $\mathrm{Sec}$ & \\
\hline Acel_0846 & 33 & NLPC_P60-GH23 & Lytic transglycosylase & M & $\mathrm{N}$ & $\mathrm{Sec}$ & \\
\hline Acel_0970 & 95 & GH9-C̄BM3-СBM2 & Beta-1,4-endoglucanase & Cel & $\mathrm{N}$ & $\mathrm{Sec}$ & \\
\hline Acel_1143 & 71 & $\mathrm{GH} 15$ & Trehalase/glucoamylase/glucodextranase & $\mathrm{G} / \mathrm{T}$ & $\mathrm{N}$ & Cyt & \\
\hline Acel_1157 & 41 & $\mathrm{GH} 23$ & Lytic transglycosylase & M & $\mathrm{N}$ & u & \\
\hline Acel_1363 & 38 & $\mathrm{GH} 32$ & Putative beta-fructosidase & M & $\mathrm{N}$ & Cyt & \\
\hline Acel_1372 & 80 & CBM48-GH13 & Glycogen debranching enzyme $G \lg X$ & $\mathrm{G} / \mathrm{T}$ & $\mathrm{N}$ & Cyt & \\
\hline Acel_1373 & 85 & $\mathrm{GH} 13$ & Malto-oligosyltrehalose synthase & $\mathrm{G} / \mathrm{T}$ & $\mathrm{N}$ & Cyt & \\
\hline Acel_1374 & 64 & CBM48-GH13 & Malto-oligosyltrehalose trehalohydrolase & $\mathrm{G} / \mathrm{T}$ & $\mathrm{N}$ & Cyt & \\
\hline Acel_1458 & 47 & GH18-CBM16 & Chitinase (EC 3.2.1.14) & Fun & $\mathrm{N}$ & SW & \\
\hline Acel_1459 & 26 & CBM16 & Carbohydrate-binding CenC domain protein & Fun & $\mathrm{Y}$ & $\mathrm{U}$ & \\
\hline Acel_1460 & 80 & GH18-CBM5-CBM16 & Chitinase (EC 3.2.1.14) & Fun & $\mathrm{Y}$ & SW & \\
\hline Acel_1601 & 83 & $\mathrm{GH} 77$ & 4-Alpha-glucanotransferase (EC2.4.1.25) & M & $\mathrm{N}$ & Cyt & \\
\hline Acel_1659 & 93 & GH3-GH3C-PA14-GH3C & Beta-glucosidase (EC3.2.1.21) & Cel & $\mathrm{Y}$ & $\mathrm{Sec}$ & \\
\hline Acel_1701 & 120 & GH9-CBM3-СBM3-СBM2 & Endoglucanase & Cel & $\mathrm{Y}$ & $\mathrm{Sec}$ & \\
\hline Acel_1868 & 31 & CE14 & Putative deacetylase & M & $\mathrm{N}$ & Cyt & \\
\hline Acel_1886 & 36 & CE14 & Putative deacetylase & M & $\mathrm{N}$ & Cyt & \\
\hline Acel_1917 & 27 & CE4 & Putative chitooligosaccharide deacetylase & Fun & $\mathrm{N}$ & Cyt & \\
\hline Acel_2033 & 61 & GH18-CBM5-CBM16 & Chitinase (EC 3.2.1.14) & Fun & $\mathrm{Y}$ & SW & \\
\hline Acel_2045 & 35 & CE7 & Acetyl xylan esterase & Hem & $\mathrm{N}$ & U & \\
\hline Acel_2050 & 88 & $\mathrm{GH} 3-\mathrm{GH} 3 \mathrm{C}$ & Beta-D-xylosidase (EC 3.2.1.37) & Hem & $\mathrm{N}$ & Cyt & \\
\hline
\end{tabular}

${ }^{a}(\mathrm{MW})$ Calculated molecular weight of the protein in kilodaltons, rounded to a whole number.

bDomain architecture was deciphered using the CAZy database (Henrissat 1991; Coutinho and Henrissat 1999) (http://www.cazy.org/) and the Conserved Domains Search tool (http://www.ncbi.nlm.nih.gov/Structure/cdd/wrpsb.cgi) (Marchler-Bauer et al. 2007). The GH (glycoside hydrolase), CBM (carbohydrate binding module), and CE (carbohydrate esterase) family numbers are based on the CAZy classification.

${ }^{c} \mathrm{~A}$ predicted role for the enzyme in (Cel) cellulose, (Hem) hemicellulose, and (Fun) fungal cell wall degradation. (G/T) Glycogen/trehalose metabolism; (M) cellular metabolism.

d (Sig) Signal peptide; the $(\mathrm{Y})$ presence or $(\mathrm{N})$ absence of a predicted signal peptide in the protein sequence. The SignalP 3.0 software was used to predict the occurrence of signal peptides (Bendtsen et al. 2004).

${ }^{e}$ (Loc) Localization. The pSORTb prediction software (Gardy et al. 2005) (http://www.psort.org/psortb/) was used to predict the subcellular localization of the protein. (Cyt) Cytoplamic; (Sec) secreted/extracellular; (U) unknown localization. (SW) Proteins are predicted to be secreted as well as cell-wallassociated; therefore, they could occupy multiple locations.

fReferences: (1) Baker et al. (1994); (2) Ding et al. (2003).

constitute an operon that encodes fumarate reductase/succinate dehydrogenase, aryldialkylphosphatase, a short-chain dehydrogenase, deoxyribose-phosphate aldolase, and a ROK-family protein, respectively. The second half of GI1 contains genes involved in sugar uptake and metabolism.

GI2 contains 18 genes (average G+C of $62.5 \%$ ) flanked by tRNA genes (Table 3). Half of the genes do not have a recognizable function, while many of the remaining genes encode putative homologs of the $v r l$ locus of Dichelobacter nodosus. The VrlI and $\mathrm{J}$ homologs in A. cellulolyticus have DNA-binding and ATPase domains, respectively, and the $\mathrm{VrlK}, \mathrm{P}$, and Q homologs do not have any identifiable domains. With respect to the four intervening proteins, one is a transcriptional regulator containing a helix-turn-helix motif, another shows weak homology with DNA methylases, a third is a hypothetical protein, and the fourth has a helicase domain and could be a VrlO homolog although the homology is undetectable at sequence level. Most proteins encoded in this island show highest similarity to proteins from low G+C Gram-positives, namely, Bacteroides, Nitrosococcus, and Thermoanerobacter.

\section{Genome Research www.genome.org}




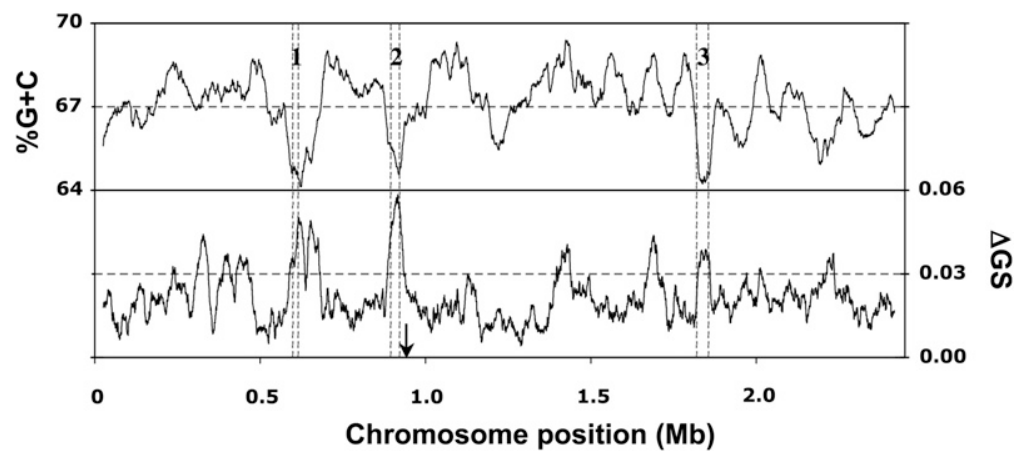

Figure 2. Genomic signature plot. A sliding window plot of the percent $\mathrm{G}+\mathrm{C}$ content (top line, $y$-axis on the left) as well as the deviation in genomic signature ( $\Delta \mathrm{GS}$; bottom line, secondary $y$-axis on right) along the chromosome. Regions 1, 2, and 3 on the plot indicate the location of the three Gls: GI1, GI2, and $\mathrm{GI} 3$, respectively. Arrow indicates the location of the flagellar and motility genes.

GI3 carries 31 genes (average $\mathrm{G}+\mathrm{C}$ of $61.7 \%$ ) and is flanked by the $t R N A^{A r g}$ gene upstream and by the $t R N A^{H i s}$ gene downstream (Table 3). One-third of the proteins encoded on this island have no recognizable function. Of the remaining genes, three encode proteins involved in $\mathrm{ABC}$ transport, two of which may be involved in the uptake of amino acids. Acel_1633-Acel_1639 form an operon of seven genes: The first two genes encode proteins with unknown function; the third and the last encode enzymes involved in amino acid metabolism; while the rest encode subunits of the carbon monoxide (CO) dehydrogenase family proteins. Another likely operon of four genes encodes an aldehyde oxidase, a coenzyme A transferase, glutaconate coA-transferase, and a luciferase family protein. Six genes in this GI (namely, Acel_1626, Acel_1628, Acel_1634, Acel_1639, Acel_1643, and Acel_1644) encode proteins that bear highest sequence similarity to proteins from thermophilic bacteria and archaea. With the exception of Acel_1626, homologs of these six proteins do not occur in Frankia.

In addition to the three major islands, 21 smaller genomic regions (GRs) were identified. Characteristics of the predicted regions are detailed in Supplemental Table S3.

\section{Flagella and motility}

Mohagheghi et al. (1986) reported that A. cellulolyticus cells were nonmotile based on microscopic observations. Surprisingly, immediately downstream from GI2, we identified a stretch of 37 genes (Acel_0828-Acel_0864) that did not have any homologs in Frankia, Streptomyces, or $T$. fusca. This region encoded a complete set of genes coding for flagellar biosynthesis and motility. The genes are organized into two divergent gene clusters (Fig. 3). Most of the flagellar structural genes are organized in the larger cluster containing 31 genes on the leading strand. The regulatory gene $\operatorname{csr} A$, recently shown to encode a regulator of flagellar biosynthesis (Yakhnin et al. 2007), is encoded by the last gene in the smaller cluster containing five genes. Thus far, only three other actinomycetes-Nocardioides sp. JS514, Kineococcus radiotolerans, and Leifsonia xyli-encode sequence homologs of the flagellar genes (Fig. 3). The gene content and order of the flagellar operon is highly conserved between A. cellulolyticus and Nocardioides, while minor differences in gene order are observed in Kineococcus. Several flagellar genes in $L$. xyli are pseudogenes, in agreement with the observation that the organism is nonmotile and does not produce a flagellum (Monteiro-Vitorello et al. 2004); the presence of motility or flagella has not been well studied in the other two organisms. Although in the original study no motility was observed in $A$. cellulolyticus (Mohagheghi et al. 1986), the possibility of motility, perhaps under specific growth conditions, is being carefully reexamined.

\section{Thermoadaptation}

Principal component analysis (PCA) of global as well as synonymous codon usage revealed that $A$. cellulolyticus, surprisingly, did not contain patterns typically observed in thermophilic prokaryotes (Supplemental Fig. S3A,B). It was clearly positioned amidst mesophiles along the PC2 axis that correlated with OGT. Codon usage differences between Acidothermus and Frankia were very subtle (Supplemental Table S4). Differences in the codon usage of the six actinobacteria compared in our study did not always follow differences in $\mathrm{G}+\mathrm{C}$ content in the coding region of their genomes (Supplemental Table S4), suggesting a physiological pressure influencing these differences. A detailed comparison of the relative abundances of the four nucleotides at each of the three codon positions showed that the relative proportion of $G$ was higher and that of $A$ was lower at the first codon position in the two thermophiles as compared to the four mesophiles (Table 4). In addition, an opposite but slightly weaker trend was observed at the third codon position, that is, the relative proportion of A was higher and that of $G$ was lower in the two thermophiles as compared to the mesophiles (Table 4). Interesting differences were observed for the GNA and ANG codons (see Supplemental Table S4). Of the four GNA codons, the GAA codon (for glutamate) showed the most prominent increase in the two thermophiles. Of the four ANG codons, the AGG codon (for arginine) was clearly less preferred in A. cellulolyticus and T. fusca.

Noncoding RNAs, ribosomal RNAs (rRNAs), and transfer RNA (tRNAs), in A. cellulolyticus had a higher $\mathrm{G}+\mathrm{C}$ content than mesophilic species with similar genomic $\mathrm{G}+\mathrm{C}$ (Fig. 4). Confidence intervals of the prediction of a linear model (RNA G+C content as a function of genomic $\mathrm{G}+\mathrm{C}$ content) for mesophilic species showed that $A$. cellulolyticus was clearly an outlier when compared to the mesophilic species in the study. The G+C content of functional RNAs has been shown to correlate positively with OGT (Galtier and Lobry 1997).

Similar to the codon-usage PCA results (Supplemental Fig. $\mathrm{S} 3 \mathrm{~A}, \mathrm{~B}), \mathrm{PCA}$ of the amino acids usage did not reveal thermophilic trends in the A. cellulolyticus proteome (Supplemental Fig. S4). Contrary to our expectation that it should segregate with other thermophiles, A. cellulolyticus was positioned near mesophiles along the PC2 axis that correlated with OGT. However, in a more detailed analysis of the amino acid composition of ribosomal proteins, A. cellulolyticus was placed nearer to the thermophiles than Frankia or Streptomyces and was at the same level as T. fusca (Fig. 5).

The total fractions of IVYWREL amino acids in the $A$. cellulolyticus proteome and cytosolic subproteome were higher than those in Frankia sp. and Streptomyces sp. (Supplemental Table S5). Furthermore, analysis of the amino acid composition of 478 conserved orthologous proteins in these six actinobacteria clearly revealed that both A. cellulolyticus and T. fusca orthologs contain 
Barabote et al.

Table 3. Genes encoded on the three genomic islands found in the A. cellulolyticus 11B genome

\begin{tabular}{|c|c|c|c|c|c|}
\hline Locus tag & $\mathbf{S}$ & Percent GC & Size & Product description & Function \\
\hline \multicolumn{6}{|c|}{ Genomic Island 1} \\
\hline Acel_0569 & + & 58.7 & 446 & Fumarate reductase/succinate dehydrogenase flavoprotein & Respiration \\
\hline Acel_0570 & + & 53.5 & 333 & Aryldialkylphosphatase & Organophosphate detoxification \\
\hline Acel_0571 & + & 57.6 & 288 & Short-chain dehydrogenase/reductase SDR & Metabolism \\
\hline Acel_0572 & + & 59.7 & 236 & Deoxyribose-phosphate aldolase & Nucleotide metabolism \\
\hline Acel_0573 & + & 62.8 & 342 & ROK family protein & Repressor/kinase/ORF \\
\hline Acel_0574 & - & 59.3 & 254 & Transcriptional regulator, GntR family & Regulation \\
\hline Acel_0575 & - & 61.9 & 421 & ROK family protein & Repressor/kinase/ORF \\
\hline Acel_0576 & + & 58.2 & 283 & SIS (Sugar ISomerase) phosphosugar binding domain protein & Carbohydrate metabolism \\
\hline Acel_0577 & + & 58.9 & 359 & Periplasmic binding protein/Lacl transcriptional regulator & $A B C$ transport \\
\hline Acel_0578 & + & 59.0 & 489 & $A B C$ transporter related & $A B C$ transport \\
\hline Acel_0579 & + & 58.6 & 335 & Inner-membrane translocator & $A B C$ transport \\
\hline Acel_0580 & + & 56.6 & 330 & Inner-membrane translocator & $A B C$ transport \\
\hline Acel_0581 & + & 58.9 & 391 & Oxidoreductase domain protein & \\
\hline Acel_0582 & + & 53.8 & 306 & Xylose isomerase domain protein TIM barrel & Sugar interconversion \\
\hline Acel_0583 & - & 59.1 & 397 & Oxidoreductase domain protein & Metabolism \\
\hline \multicolumn{6}{|c|}{$\begin{array}{l}\text { Genomic Island } 2 \\
\text { Acel R0021 }\end{array}$} \\
\hline Acel_0810 & + & 59.0 & 61 & DNA binding domain, excisionase family & Vrll homolog \\
\hline Acel_0811 & + & 59.3 & 159 & Conserved hypothetical protein & VrlJ homolog \\
\hline Acel_0812 & + & 62.6 & 1244 & Conserved hypothetical protein & VrIK homolog \\
\hline Acel_0813 & + & 61.0 & 468 & Putative transcriptional regulator & Transcriptional regulation \\
\hline Acel_0814 & + & 60.5 & 993 & Conserved hypothetical protein & \\
\hline Acel_0815 & + & 51.1 & 268 & Hypothetical protein & \\
\hline Acel_0816 & + & 64.7 & 934 & Helicase domain protein & VrlO homolog? \\
\hline Acel_0817 & + & 57.5 & 678 & Conserved hypothetical protein & VrIP homolog \\
\hline Acel_0818 & + & 57.0 & 261 & Conserved hypothetical protein & VrlQ homolog \\
\hline Acel_0819 & + & 67.2 & 64 & Hypothetical protein & \\
\hline Acel_0820 & + & 68.8 & 446 & Metallophosphoesterase & DNA repair \\
\hline Acel_0821 & + & 67.6 & 918 & SMC domain protein & DNA repair \\
\hline Acel_0822 & + & 66.7 & 502 & Acyltransferase 3 & Metabolic enzyme \\
\hline Acel_0823 & - & 66.5 & 548 & Diguanylate cyclase/phosphodiesterase & Metabolic enzyme \\
\hline Acel_0824 & - & 65.0 & 122 & Hypothetical protein & \\
\hline Acel_0825 & - & 66.2 & 206 & Protein of unknown function DUF421 & \\
\hline Acel_R0022 & + & 66.2 & & Met tRNA & \\
\hline \multicolumn{6}{|c|}{ Genomic Island 3} \\
\hline Acel_R0044 & + & 68.5 & & Arg tRNA & \\
\hline Acel_1621 & + & 51.1 & 92 & Hypothetical protein & \\
\hline Acel_1622 & + & 62.8 & 162 & Hypothetical protein & \\
\hline Acel_1623 & + & 64.0 & 89 & Transcriptional regulator, XRE family & Transcriptional regulation \\
\hline Acel_1624 & + & 55.7 & 176 & Hypothetical protein & \\
\hline Acel_1625 & + & 66.5 & 180 & Hypothetical protein & \\
\hline Acel_1626 & + & 63.3 & 230 & $A B C$ transporter related & Transport \\
\hline Acel_1627 & + & 65.8 & 426 & Protein of unknown function DUF214 & \\
\hline Acel_1628 & + & 63.7 & 168 & Methylglyoxal synthase & Enzyme \\
\hline Acel_1629 & - & 64.9 & 483 & Methyl-accepting chemotaxis sensory transducer & Chemotaxis \\
\hline Acel_1630 & - & 65.9 & 213 & Conserved hypothetical protein & \\
\hline Acel_1631 & - & 65.5 & 358 & Protein of unknown function DUF182 & \\
\hline Acel_1632 & - & 54.8 & 208 & Conserved hypothetical protein & \\
\hline Acel_1633 & - & 58.9 & 602 & Purine catabolism PucR domain protein & Purine degradation regulator \\
\hline Acel_1634 & - & 59.6 & 327 & Conserved hypothetical protein & \\
\hline Acel_1635 & - & 61.7 & 403 & Pyridoxal-5'-phosphate-dependent enzyme, beta subunit & Metabolic enzyme \\
\hline Acel_1636 & - & 62.2 & 238 & Carbon monoxide dehydrogenase subunit G, CoxG & CO fixation? \\
\hline Acel_1637 & - & 59.7 & 162 & Carbon monoxide dehydrogenase small subunit, CoxS & CO fixation? \\
\hline Acel_1638 & - & 61.4 & 296 & Carbon monoxide dehydrogenase (acceptor), CoxM & CO fixation? \\
\hline Acel_1639 & - & 59.2 & 231 & Asp/Glu racemase & Amino acid metabolism \\
\hline Acel_1640 & - & 58.9 & 560 & Polar amino acid $A B C$ transporter, inner membrane subunit & Amino acid transport \\
\hline Acel_1641 & - & 57.2 & 303 & Extracellular solute-binding protein, family 3 & Solute uptake \\
\hline Acel_1642 & - & 61.0 & 783 & Aldehyde oxidase and xanthine dehydrogenase & Metabolic enzyme \\
\hline Acel_1643 & - & 60.4 & 262 & Coenzyme A transferase & Metabolic enzyme \\
\hline Acel_1644 & - & 59.6 & 318 & Glutaconate CoA-transferase & Metabolic enzyme \\
\hline Acel_1645 & - & 55.6 & 316 & Luciferase family protein & Metabolic enzyme \\
\hline Acel_1646 & + & 62.8 & 230 & NADPH-dependent F420 reductase & Metabolic enzyme \\
\hline Acel_1647 & + & 67.7 & 505 & Malate dehydrogenase (oxaloacetate-decarboxylating) & Metabolic enzyme \\
\hline Acel_1648 & + & 66.1 & 363 & Molybdenum cofactor biosynthesis protein A & Metabolic enzyme \\
\hline Acel_1649 & + & 69.5 & 270 & Exonuclease, RNase T, and DNA polymerase III & Metabolic enzyme \\
\hline Acel_R0045 & + & 59.2 & & His tRNA & \\
\hline
\end{tabular}

$+/$ - Indicates the DNA strand (S) that encodes the gene. The boxes indicate blocks of genes on the same strand with intergenic distance $<50$ bp. Size indicates the length of the predicted protein in amino acids. Product descriptions are based on automatic annotation of the gene. The last column provides a broad function of the protein.

\section{Genome Research www.genome.org}




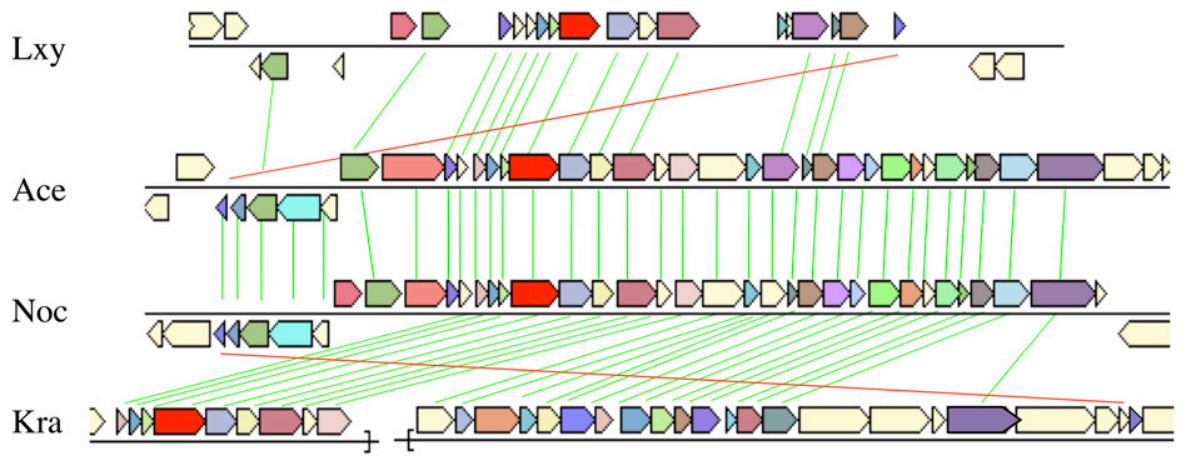

Figure 3. Synteny and gene organization of the flagellar biosynthetic genes in actinobacteria. The $A$. cellulolyticus locus Acel_0827-Acel_0864 is displayed; the syntenic region ranges from Acel_0829 to Acel_0861. Ace, Kra, Lxy, and Noc denote A. cellulolyticus, K. radiotolerans, L. xyli, and Nocardioides sp. JS614, respectively. Chromosomal gene organization from each of the completely assembled genomes is shown, except in the case of $K$. radiotolerans, for which genes from two different contigs are shown. Therefore, the true order of the whole region in $K$. radiotolerans remains unclear. Synteny between the different chromosomal regions is indicated by green lines (for genes on the same strand) and red lines (for genes on opposite strands). The gene sizes in the different organisms are not drawn to scale. Also, the $K$. radiotolerans genes are colored differently than the genes in the other three organisms.

contrast, many of the terrestrial as well as aquatic actinobacterial relatives of $A$. cellulolyticus, such as Frankia sp., S. avermitilis, $S$. coelicolor, and T. fusca (see Table 1) as well as $K$. radiotolerans, and Nocardioides sp. (data not shown) possess multiple pseudogenes, as well as several transposase-encoding genes and interior sequence (IS) elements in their genomes. With the exception of $T$. fusca, the other actinobacteria also possess large genomes, ranging from 5 to $9 \mathrm{Mb}$. It is conceivable that the presence and abundance of transposase-related genes in the larger genomes reflect the role of these mobile elements in their genome expansion, as described for Frankia (Normand et al. 2007), but also that genome reduction events accompanied by the loss of mobile elements may have resulted in a small genome size of $A$. cellulolyticus.

With the renewed interest and

a higher proportion of IVYWREL amino acids compared to the four mesophilic organisms (Supplemental Table S5). The values of IVYWREL fractions in the orthologs showed even greater linear correlation with OGT than those from the cytosolic subproteomes or whole proteomes. In addition, an extended analysis of 46 conserved orthologous proteins from several mesophilic and thermophilic actinobacteria with varying $\mathrm{G}+\mathrm{C}$ content showed a similar trend, namely, that orthologs from the thermophilic actinobacteria contain increased representation of IVYWREL amino acids compared to the mesophiles (Supplemental Table S6). It is to be noted that there are exceptions to a strict increase in IVYWREL with OGT. Thus, the content of IVYWREL is a reasonable but not a perfect predictor of the OGT, as noted also by Zeldovich et al. (2007).

\section{Discussion}

A. cellulolyticus has a small genome with very few pseudogenes or mobile genetic elements. The two transposase-encoding gene sequences in A. cellulolyticus encode frame-shifted fragments of an intact gene that is found in Frankia and other actinobacteria. As a result, $A$. cellulolyticus may not encode an active transposase. In growing quest for microbes that efficiently deconstruct plant cell wall carbohydrates for conversion to biofuels, the sequenced genome of $A$. cellulolyticus offers substantial potential for the discovery of valuable thermostable enzymes. In addition to five previously described cellulolytic enzymes, the A. cellulolyticus genome revealed many additional possibilities for biomass degradation. The A. cellulolyticus genome encodes genes for several enzymes that break down cellulose and xylans, while the absence of pectin degradation genes corroborates the reported lack of growth on pectin (Mohagheghi et al. 1986). The organism devotes about equal numbers of enzymes to the breakdown of cellulose (10 genes) and xylan (seven genes) in the plant cell wall, as well as chitin and other components in fungal cell walls (10 genes), and the metabolism of storage carbohydrates such as glycogen and trehalose (eight genes). This suggests that all these carbon sources are of comparable importance to the organism.

Complete enzymatic digestion of cellulose requires three types of glycosyl hydrolases, including cellulases (endoglucanases), cellobiohydrolases (exoglucanases), and cellobiosidases (beta-glucosidases). All three are present in multiple copies in the A. cellulolyticus genome. Specifically, there are six endoglucanases, two exoglucanases, and two beta-glucosidases. Efficient hydrolysis of crystalline cellulose requires the presence of at least

Table 4. Relative proportions of each nucleotide at each of the three codon positions in six actinobacteria

\begin{tabular}{|c|c|c|c|c|c|c|c|c|c|c|c|c|c|}
\hline \multirow[b]{3}{*}{ Organism } & \multirow{3}{*}{$\begin{array}{l}\text { OGT } \\
\left({ }^{\circ} \mathrm{C}\right)\end{array}$} & \multicolumn{12}{|c|}{ Nucleotide and codon base position } \\
\hline & & \multicolumn{4}{|c|}{ Position 1 (5'-end) } & \multicolumn{4}{|c|}{ Position 2 (middle) } & \multicolumn{4}{|c|}{ Position 3 (3'-end) } \\
\hline & & A & C & G & $\mathbf{T}$ & A & C & G & $\mathbf{T}$ & A & C & G & $\mathbf{T}$ \\
\hline A. cellulolyticus 11B & 55 & 0.362 & 0.280 & 0.425 & 0.235 & 0.457 & 0.291 & 0.213 & 0.533 & 0.181 & 0.429 & 0.362 & 0.232 \\
\hline Frankia alni ACN14 & 28 & 0.388 & 0.267 & 0.413 & 0.255 & 0.514 & 0.278 & 0.213 & 0.621 & 0.098 & 0.455 & 0.374 & 0.124 \\
\hline Frankia sp. Ccl3 & 27 & 0.382 & 0.277 & 0.408 & 0.247 & 0.487 & 0.282 & 0.216 & 0.580 & 0.131 & 0.441 & 0.376 & 0.173 \\
\hline S. avermitilis MA-4680 & 28 & 0.384 & 0.261 & 0.412 & 0.274 & 0.518 & 0.269 & 0.206 & 0.617 & 0.098 & 0.469 & 0.382 & 0.109 \\
\hline S. coelicolor A3(2) & 30 & 0.381 & 0.258 & 0.417 & 0.275 & 0.534 & 0.264 & 0.208 & 0.644 & 0.086 & 0.478 & 0.375 & 0.081 \\
\hline T. fusca YX & 50 & 0.357 & 0.272 & 0.424 & 0.256 & 0.481 & 0.265 & 0.212 & 0.591 & 0.163 & 0.463 & 0.364 & 0.153 \\
\hline$R$-squared value & & 0.900 & 0.331 & 0.885 & 0.342 & 0.631 & 0.085 & 0.024 & 0.521 & 0.795 & 0.196 & 0.854 & 0.484 \\
\hline$P$-value less than & & 0.004 & 0.232 & 0.005 & 0.223 & 0.059 & 0.575 & 0.772 & 0.105 & 0.017 & 0.380 & 0.008 & 0.125 \\
\hline
\end{tabular}

Regression ( $R$-squared) and $P$-values were calculated using the $\mathrm{R}$ software. A $P$-value $<0.05$ is considered significant. 


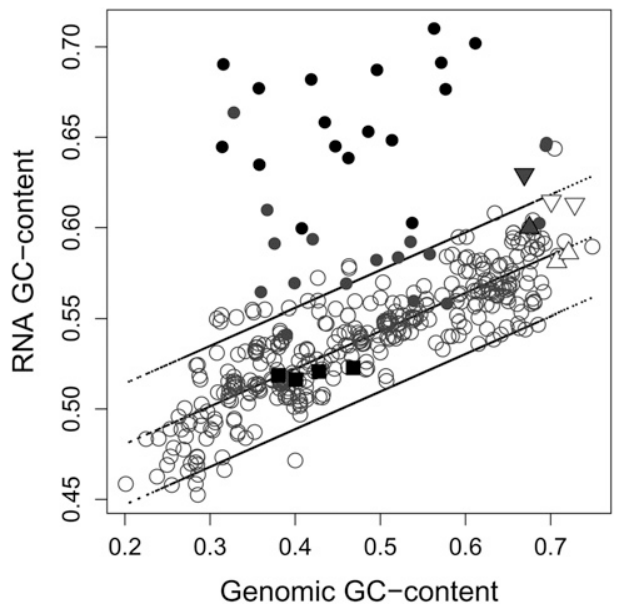

Figure 4. Plot of the $\mathrm{G}+\mathrm{C}$ content of noncoding RNAs (rRNA + tRNAs) versus the $\mathrm{G}+\mathrm{C}$ of genome in prokaryotes. The following shapes and shades are used for distinguishing the organisms: black circles, hyperthermophiles; dark gray circles, thermophiles; open circles, mesophiles; filled squares, psychrophiles; inverted gray triangle, A. cellulolyticus; gray triangle, T. fusca; inverted open triangles, two Frankia sp. (ACN14a, Ccl3), and open triangles, two Streptomyces sp. (S. avermitilis, S. coelicolor). Black lines represent the regression line and $95 \%$ confidence intervals, computed for the mesophiles.

one endoglucanase and two types of exoglucanases. The Acidothermus genome contains both a reducing-end-specific GH48 exoglucanase and a nonreducing-end-specific GH6 exocellulase (Ding et al. 2003).

Based on sequence similarity of the A. cellulolyticus Acel 0129 protein to a characterized endo-1,3-beta-glucanase from Streptomyces sioyaensis, we predict that this protein binds to and hydrolyzes 1,3-beta-D-glucan, a major constituent of fungal cell walls and laminarins of certain algal groups and diatoms (Hong et al. 2002). This enzyme likely helps the organism assimilate fungal cell walls as a food source. The functions of four putative chitinases remain to be confirmed experimentally. The capability to degrade chitin could permit degradation of fungal and insect biomass. After cellulose, chitin is the second most abundant structural cell wall polymer in nature. Unlike other eukaryotic cellwall biopolymers, chitin contains nitrogen and hence could be used as a carbon and nitrogen source. Decaying plant matter as well as dead insects that fall into the thermal pools may provide sources of chitin and 1,3-beta-D-glucan. The ability to utilize a range of carbon sources could offer a survival edge under limiting nutritional conditions in the thermal pool. Chitinases have received increased attention recently owing to their wide applications in the agricultural, medical, and food industries. The potential for a source of thermostable chitinases elevates the industrial importance of $A$. cellulolyticus beyond its anticipated applications in cellulosic biofuel technologies.

The fact that secreted plant biomass-degrading enzymes in A. cellulolyticus contain two different types of CBM domains, from families 2 and 3, is interesting functionally as well as evolutionarily. Only 10 complete bacterial genomes, including $A$. cellulolyticus, encode both CBM types, of which six are Actinobacteria and one a Firmicute (http://www.cazy.org). This relatively low frequency suggests that the coexistence of both types of CBM domains is rare. Among these 10 genomes, there is a clear preference for either CBM2 (in Actinobacteria) or CBM3 (in the Firmicutes) but not for both. The A. cellulolyticus genome with equal proportions of the two CBM types is clearly an exception to the pattern to date. The coexistence of CBM2 and CBM3 domains in a majority of the A. cellulolyticus modular enzymes as well as their restricted organization may suggest functional and/or thermostability constraints. It is possible that the presence of CBM3 alone or its location C-terminal to CBM2 may either destabilize the protein or affect the optimal activity of $A$. cellulolyticus enzymes. The high degree of sequence conservation within the two CBM families in A. cellulolyticus suggests duplication of each of these domains after speciation. Fusion of these duplicated domains to the GHs could indicate a selective pressure for localizing the secreted GHs on specific substrates. Both CBM2 and CBM3 bind predominantly to cellulose, with experimental evidence for binding to chitin in a few cases (Boraston et al. 2004). A few CBM2 members have also been observed to bind xylan (Boraston et al. 2004). Whether the two families of CBM domains in A. cellulolyticus bind cellulose, xylan or chitin, or multiple substrates remains to be determined functionally.

The A. cellulolyticus genome revealed three laterally acquired GIs characterized by a lower $\mathrm{G}+\mathrm{C}$ content and a deviation from the genomic signature. Regions that deviate significantly from the genomic signature are thought to have been laterally transferred (Karlin 2001). In addition, the fact that the three islands are either flanked by tRNA genes and/or lack homologs in other actinobacteria strongly suggests that these DNA regions have been horizontally acquired in A. cellulolyticus. Several genes in these islands show highest sequence similarity to proteins from thermophilic organisms. Analysis of the genes encoded within the three GIs suggests a functional role for the acquired genes in the context of the organism's ecology. Aryldialkyl phosphatase (encoded on GI1) catalyzes the hydrolysis of an aryl-dialkyl phosphate to form dialkyl phosphate and an aryl alcohol. In cellulolytic fungi, arylalcohol dehydrogenase activity has been implicated in lignolysis (Reiser et al. 1994). GI2 carries homologs of the $v r l$ genes found preferentially associated with more virulent isolates of $D$. nodosus and that are proposed to have been acquired horizontally possibly

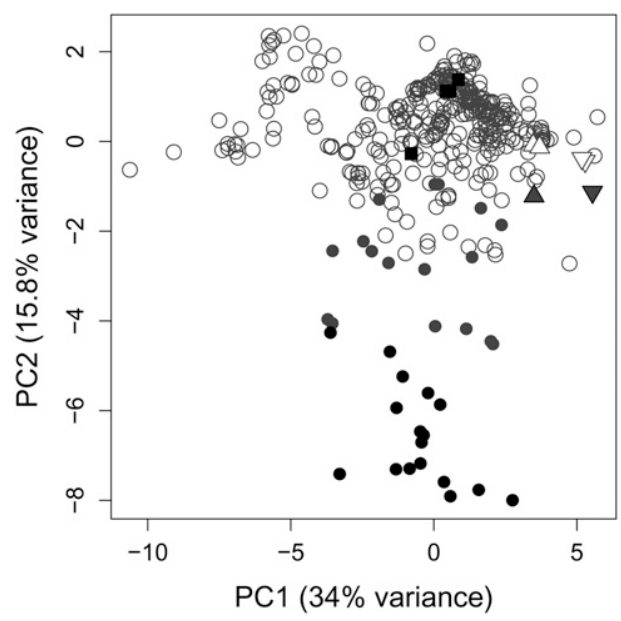

Figure 5. Reduced dimensionality plot of PCA of amino acid usage in ribosomal proteins in 409 prokaryotes. The following shapes and shades are used for distinguishing the organisms: black circles, hyperthermophiles; dark gray circles, thermophiles; open circles, mesophiles; black squares, psychrophiles; inverted gray triangle, A. cellulolyticus; gray triangle, T. fusca; inverted open triangles, two Frankia sp. (ACN14a, Ccl3), and open triangles, two Streptomyces sp. (S. avermitilis, S. coelicolor). 
from a bacteriophage or a plasmid (Billington et al. 1999). Although the precise function of the $v r l$ locus is unclear, many of these genes could be involved in DNA restriction and modification, offering immunity to $A$. cellulolyticus against phage infection, similar to the $S$. coelicolor phage-resistance Pgl system (Sumby and Smith 2002), which bears sequence similarity to the Vrl proteins. GI3 contains genes that may be involved in amino acid transport and metabolism as well as genes for three subunits of the CO dehydrogenase family. Homologs also occur in other actinobacteria such as Arthrobacter and Mycobacteria that have been shown to grow chemolithotrophically on CO as the sole carbon and energy source under aerobic conditions (Meyer and Schlegel 1983; Park et al. 2003), suggesting that a similar potential may be present in A. cellulolyticus. Since CO dehydrogenases share high sequence similarity with xanthine dehydrogenases, it is difficult to predict whether the A. cellulolyticus homologs function in carbon fixation or in purine salvage. However, either of these possibilities would add eco-physiological value for $A$. cellulolyticus.

Thermophilic adaptations have not been systematically examined within the actinobacteria, an ecologically diverse yet relatively understudied bacterial group. A. cellulolyticus grows optimally at $55^{\circ} \mathrm{C}$, while most of its closest phylogenetic relatives are mesophilic. The use of PCA, or the similar technique, correspondence analysis (CA), to study the genomes of hyperthermophilic, thermophilic, and mesophilic prokaryotes has facilitated identification of their thermoadaptation characteristics (Kreil and Ouzounis 2001; Lynn et al. 2002; Singer and Hickey 2003; Suhre and Claverie 2003). Contrary to our expectations based on these previous studies, in our PCA results, neither the genome nor the proteome of $A$. cellulolyticus segregates with other thermophiles. The degree of separation along PC2 axis that correlates with OGT may suggest how recently a thermophile has evolved. In that case, the lack of unambiguous separation of $A$. cellulolyticus from mesophiles along PC2 could reflect the relatively short history of $A$. cellulolyticus in thermal pools, as its genome and proteome still show mesothermophilic features. This pattern suggests a recent and ongoing adaptation to the thermophilic environment. Alternatively, A. cellulolyticus may have evolved unique mechanisms of thermotolerance.

The subtle increase in the $\mathrm{G}$ and A nucleotides at the first and third codon positions, respectively, in the A. cellulolyticus genes could enhance thermostability of its mRNAs by probabilistically increasing the frequency of AG dinucleotides in its mRNAs, by a plausible increase in the frequency of NNA-GNN di-codons. The ApG dinucleotides are thought to stabilize DNA because of their low stacking energy and have been observed to occur at higher frequency in (hyper)thermophilic organisms compared to mesophiles (Zeldovich et al. 2007). The relatively lower frequency of AGG codons in A. cellulolyticus may, in turn, be due to the inverse purine preferences at the first and third codon positions and may explain the lack of separation of $A$. cellulolyticus from the mesophiles, along PC2 in our PCA (see Supplemental Fig. S3A,B). The AGG codon is known to strongly influence the separation between thermophiles and mesophiles (Lynn et al. 2002; Singer and Hickey 2003). A. cellulolyticus is clearly an exception in the use of AGG codons compared to other thermophiles.

The A. cellulolyticus proteome contained an elevated fraction of IVYWREL amino acids compared to both Frankia sp. and Streptomyces sp. A recently identified positive correlation between the total fraction of seven amino acids (Ile, Val, Tyr, Trp, Arg, Glu, Leu) in prokaryotic proteomes and the OGT of the organisms is another measure for thermoadaptation (Zeldovich et al. 2007).
Usage patterns of either the 20 individual amino acids (as studied using PCA) or the total fraction of IVYWREL amino acids likely represent alternative yet overlapping thermophilic signatures. This is because most hyperthermophiles and thermophiles separate well along the OGT axis in PCA and also contain a relatively elevated content of IVYWREL residues in their proteomes. Interestingly, A. cellulolyticus appears to show the latter but not the former thermophilic signature. It is possible that the elevated IVYWREL content in the proteome represents an overarching adaptation to thermophiliy and that usages of individual amino acids get fine-tuned with evolutionary time. The higher IVYWREL content in conserved A. cellulolyticus proteins compared to their orthologs in mesophilic actinobacteria rules out the possibility that the differences in IVYWREL residues in the proteome and cytosolic subproteome are due to a few proteins with skewed amino acid composition. This suggests that this biased amino acid usage in the $A$. cellulolyticus proteome may be reflective of its adaptation to the thermal environment. It is worth noting that there have been no findings of proteins unique to thermophiles that explain organismal adaptations to high temperature, and that proteins in thermophiles show biased amino acid compositions compared to orthologs in mesophiles (Takami et al. 2004).

Adaptation to thermophily is likely to be a slow and continuous process. Although the overall A. cellulolyticus proteome revealed no clear thermophilic tendency, a more detailed analysis revealed a preference for thermophilic amino acid usage in its ribosomal proteins. These results taken together with the fact that ribosomal proteins are essential for cellular viability, and that ribosomal RNAs and transfer RNAs in A. cellulolyticus contain distinct thermophilic features, suggest that evolution of a thermotolerant protein translation machinery may be an important early step in thermoadaptation. It has been reported that three characterized strains of $A$. cellulolyticus have different OGT (Mohagheghi et al. 1986). Conceivably, other strains of $A$. cellulolyticus that span a range of either lower or higher OGT exist in nature. Perhaps, the isolation of such strains in the future and the availability of genome sequence from multiple $A$. cellulolyticus strains may shed further light on genomic evolutionary processes for thermophilic adaptation.

\section{Methods}

\section{Strains, culture, and DNA extraction}

A. cellulolyticus 11B was grown at University of California, Davis, from DMSO stocks maintained and provided by the National Renewable Energy Laboratory (NREL, Golden, CO), derived from the original isolate of Mohagheghi et al. (1986). Cells were grown in shaking or rolling liquid cultures at $55^{\circ} \mathrm{C}$, in LPBM medium (Mohagheghi et al. 1986) (also called ATCC medium 1473), $\mathrm{pH} 5.5$, modified such that the carbon source was $0.25 \mathrm{~g} / \mathrm{L}$ cellobiose $+0.25 \mathrm{~g} / \mathrm{L}$ glucose, without cellulose. For isolation of highmolecular-weight genomic DNA from A. cellulolyticus, a protocol was devised to reduce the extensive nuclease activity: Cell pellets were suspended in $200 \mu \mathrm{L}$ of lysis buffer $(50 \mathrm{mM}$ Tris- $\mathrm{HCl}, \mathrm{pH} 8.0$, $10 \mathrm{mM}$ EDTA, preheated to $\left.37^{\circ} \mathrm{C}\right)$ with $10 \mu \mathrm{L}$ of lysozyme $(100$ $\mathrm{mg} / \mathrm{mL}$; MP Biomedicals), and incubated for $2 \mathrm{~h}$ at $37^{\circ} \mathrm{C} ; 1200 \mu \mathrm{L}$ of ATL solution (QIAGEN) plus $200 \mu \mathrm{L}$ of protease $\mathrm{K}(10 \mathrm{mg} / \mathrm{mL}$; QIAGEN) were added, followed by incubation for $2.5 \mathrm{~h}$ at $55^{\circ} \mathrm{C}$. The supernatant was extracted with phenol-chloroform and chloroform, and DNA was precipitated, air-dried, and resuspended as in Sambrook et al. (1989). Genomic DNA was stored at $-20^{\circ} \mathrm{C}$ 
in the presence of $0.1 \mathrm{mg} / \mathrm{mL}$ RNase I (Promega), and its integrity was verified on $0.5 \%$ agarose gel.

\section{Sequencing, gene prediction, and annotation}

The A. cellulolyticus 11B genome (NCBI Record: NC_ 008578) was sequenced and annotated by the Joint Genome Institute, U.S. Department of Energy. Large (40 kb), medium (8 kb), and small (3 kb) insert DNA libraries were sequenced using the random shotgun method with an average success rate of $96 \%$ and average high-quality read lengths of 685 nucleotides (nt). After the shotgun stage, reads were assembled with parallel phrap (High Performance Software, LLC). Possible mis-assemblies were corrected with Dupfinisher (C. Han, unpubl.) or a transposon bomb of bridging clones (EZ-Tn5 < P6Kyori/KAN-2> Tnp Transposome kit; Epicentre Biotechnologies). Gaps between the contigs were closed by editing, custom primer walks, or PCR amplification. The completed genome sequence of $A$. cellulolyticus contains 59,147 reads, achieving an average of 18 -fold sequence coverage per base with an error rate of $<1$ in 100,000. Automated annotation steps were performed as described previously (Chain et al. 2003).

\section{Data acquisition}

Genome sequence files, executable BLAST (Altschul et al. 1997) programs, and the " $\mathrm{nr}$ " database were obtained from the NCBI ftp site. In order to build a comprehensive data set spanning the entire known range of OGTs for our PCA analyses, we extracted all complete prokaryotic genome sequences available in the NCBI genome database, without making any a priori choice of the species to be included in our analyses. OGT information was extracted from the American Tissue Culture Collection (ATCC) and the German Collection of Microorganisms and Cell Cultures (DSMZ). Organisms with unknown OGT were removed, and our final data set contained 409 prokaryotes (Supplemental Table S7), including 17 hyperthermophilic species (OGT $\geq 80^{\circ} \mathrm{C}$ ), 19 thermophilic species (OGT between $55^{\circ} \mathrm{C}$ and $80^{\circ} \mathrm{C}$ ), 369 mesophiles (OGT between $20^{\circ} \mathrm{C}$ and $55^{\circ} \mathrm{C}$ ), and four psychrophiles (OGT < $20^{\circ} \mathrm{C}$ ).

To extract ribosomal proteins, we scanned the annotations of the complete genomes listed in the NCBI ftp sites for the following terms: "ribosomal," "50S," "30S," "SSU," or "LSU." We then manually checked the annotations retrieved with this method, and we removed hits that did not correspond to ribosomal proteins per se (e.g., "ribosomal large subunit pseudouridine synthase $\left.\mathrm{D}^{\prime \prime}\right)$.

\section{Sequence analyses}

The percent $\mathrm{G}+\mathrm{C}$ of the genome and the noncoding RNAs were calculated from nucleotide sequences in the respective NCBI files. Short Perl codes were written and used for specific computational tasks, such as for calculating $\mathrm{G}+\mathrm{C}$ in DNA and RNA sequences, amino acid composition of proteins, codon usage, and the like. The total fraction of IVYWREL residues was calculated by combining the fractions of the seven individual amino acids. The relative proportions of each nucleotide at each codon position were calculated from the codon usage tables. The genomic signature was calculated as described by Karlin (2001). The organization of flagellar genes in the different actinobacteria was obtained using the tools available on the Integrated Microbial Genomics (IMG) server (http://img.jgi.doe.gov/cgi-bin/pub/main.cgi) (Markowitz et al. 2006).

All A. cellulolyticus proteins were searched against the $\mathrm{nr}$ database using the standalone BLASTP program, and the distri- bution of organisms with the best hit was calculated from the BLAST results. Bidirectional top BLAST hits were used to identify the 478 conserved proteins (Supplemental Table S8) in six organisms listed in Table 1 . Similarly, 46 orthologous proteins (Supplemental Table S9) were identified common to 45 completely sequenced actinobacteria.

\section{Principal component analysis (PCA)}

The amino acid compositions of ribosomal proteins from 409 prokaryotes with known OGTs were subjected to PCA using the R statistical software (http://www.r-project.org/). Global and synonymous codon usage in the genomes and amino acid usage in the whole proteomes of the 409 prokaryotes were also analyzed using PCA (see Supplemental Material). All statistical analyses were performed using the inbuilt functions in the $\mathrm{R}$ package (http://www.r-project.org/).

\section{Acknowledgments}

This work was supported by a Microbial Sequencing Project, U.S. Department of Energy, proposed by A.M.B., and Experiment Station Project CA-D*-PLS-7688-H (A.M.B.). We thank Charlie Strauss and Chris Stubben at the Los Alamos National Laboratory for help with PCA and R software, respectively.

\section{References}

Adney, W.S., Tucker, M.P., Nieves, R.A., Thomas, S.R., and Himmel, M.E. 1995. Low molecular weight thermostable $\beta$-D-glucosidase from Acidothermus cellulolyticus. Biotechnol. Lett. 17: 49-54.

Alloisio, N., Marechal, J., Heuvel, B.V., Normand, P., and Berry, A.M. 2005. Characterization of a gene locus containing squalene-hopene cyclase $(s h c)$ in Frankia alni ACN14a, and an shc homolog in Acidothermus cellulolyticus. Symbiosis 39: 83-90.

Altschul, S.F., Madden, T.L., Schäffer, A.A., Zhang, J., Zhang, Z., Miller, W., and Lipman, D.J. 1997. Gapped BLAST and PSI-BLAST: A new generation of protein database search programs. Nucleic Acids Res. 25: 3389-3402.

Baker, J.O., Adney, W.S., Nieves, R.A., Thomas, S.R., Himmel, M.E., and Wilson, D.B. 1994. A new thermostable endoglucanase, Acidothermus cellulolyticus E1. Appl. Biochem. Biotechnol. 45-46: 245-256.

Bendtsen, J.D., Nielsen, H., von Heijne, G., and Brunak, S. 2004. Improved prediction of signal peptides: SignalP 3.0. J. Mol. Biol. 340: 783-795.

Benson, D.R. 1988. The genus Frankia: Actinomycete symbionts of plants. Microbiol. Sci. 5: 9-12.

Bentley, S.D., Chater, K.F., Cerdeno-Tarraga, A.M., Challis, G.L., Thomson, N.R., James, K.D., Harris, D.E., Quail, M.A., Kieser, H., Harper, D., et al. 2002. Complete genome sequence of the model actinomycete Streptomyces coelicolor A3(2). Nature 417: 141-147.

Billington, S.J., Huggins, A.S., Johanesen, P.A., Crellin, P.K., Cheung, J.K., Katz, M.E., Wright, C.L., Haring, V., and Rood, J.I. 1999. Complete nucleotide sequence of the 27-kilobase virulence related locus ( $\mathrm{vrl}$ ) of Dichelobacter nodosus: Evidence for extrachromosomal origin. Infect. Immun. 67: 1277-1286.

Boraston, A.B., Bolam, D.N., Gilbert, H.J., and Davies, G.J. 2004. Carbohydrate-binding modules: Fine tuning polysaccharide recognition. Biochem. J. 382: 769-781.

Chain, P., Lamerdin, J., Larimer, F., Regala, W., Lao, V., Land, M., Hauser, L., Hooper, A., Klotz, M., Norton, J., et al. 2003. Complete genome sequence of the ammonia-oxidizing bacterium and obligate chemolithoautotroph Nitrosomonas europaea. J. Bacteriol. 185: 2759-2773.

Coutinho, P.M. and Henrissat, B. 1999. Carbohydrate-active enzymes: An integrated database approach. In Recent advances in carbohydrate bioengineering (eds. H.J. Gilbert et al.), pp. 3-12. The Royal Society of Chemistry, Cambridge, UK.

Ding, S.-Y., Adney, W.S., Vinzant, T.B., Decker, S.R., Baker, J.O., Thomas, S.R., and Himmel, M.E. 2003. Glycoside hydrolase gene cluster of Acidothermus cellulolytics. In Applications of enzymes to lignocellulosics (eds. S. Mansfield and J.N. Saddler), ACS Symposium Series 855, pp. 332-360. American Chemical Society, Washington, DC. 
Galtier, N. and Lobry, J.R. 1997. Relationships between genomic G+C content, RNA secondary structures, and optimal growth temperature in prokaryotes. J. Mol. Evol. 44: 632-636.

Gardy, J.L., Laird, M.R., Chen, F., Rey, S., Walsh, C.J., Ester, M., and Brinkman, F.S.L. 2005. PSORTb v.2.0: Expanded prediction of bacterial protein subcellular localization and insights gained from comparative proteome analysis. Bioinformatics 21: 617-623.

Henrissat, B. 1991. A classification of glycosyl hydrolases based on aminoacid sequence similarities. Biochem. J. 280: 309-316.

Hong, T.Y., Cheng, C.W., Huang, J.W., and Meng, M. 2002. Isolation and biochemical characterization of an endo-1,3-beta-glucanase from Streptomyces sioyaensis containing a C-terminal family 6 carbohydratebinding module that binds to 1,3-beta-glucan. Microbiology 148: 11511159.

Ikeda, H., Ishikawa, J., Hanamoto, A., Shinose, M., Kikuchi, H., Shiba, T., Sakaki, Y., Hattori, M., and Omura, S. 2003. Complete genome sequence and comparative analysis of the industrial microorganism Streptomyces avermitilis. Nat. Biotechnol. 21: 526-531.

Karlin, S. 2001. Detecting anomalous gene clusters and pathogenicity islands in diverse bacterial genomes. Trends Microbiol. 9: 335-343.

Kreil, D.P. and Ouzounis, C.A. 2001. Identification of thermophilic species by the amino acid compositions deduced from their genomes. Nucleic Acids Res. 29: 1608-1615.

Lykidis, A., Mavromatis, K., Ivanova, N., Anderson, I., Land, M., DiBartolo, G., Martinez, M., Lapidus, A., Lucas, S., Copeland, A., et al. 2007. Genome sequence and analysis of the soil cellulolytic actinomycete Thermobifida fusca YX $\nabla$. J. Bacteriol. 189: 2477-2486.

Lynn, D.J., Singer, G.A., and Hickey, D.A. 2002. Synonymous codon usage is subject to selection in thermophilic bacteria. Nucleic Acids Res. 30: 4272-4277.

Marchler-Bauer, A., Anderson, J.B., Derbyshire, M.K., DeWeese-Scott, C., Gonzales, N.R., Gwadz, M., Hao, L., He, S., Hurwitz, D.I., Jackson, J.D., et al. 2007. CDD: A conserved domain database for interactive domain family analysis. Nucleic Acids Res. 35: D237-D240.

Marechal, J., Clement, B., Nalin, R., Gandon, C., Orso, S., Cvejic, J.H., Bruneteau, M., Berry, A., and Normand, P. 2000. A recA gene phylogenetic analysis confirms the close proximity of Frankia to Acidothermus. Int. J. Syst. Evol. Microbiol. 50: 781-785.

Markowitz, V.M., Korzeniewski, F., Palaniappan, K., Szeto, E., Werner, G., Padki, A., Zhao, X., Dubchak, I., Hugenholtz, P., Anderson, I., et al. 2006. The integrated microbial genomes (IMG) system. Nucleic Acids Res. 34: D344-D348.

Meyer, O. and Schlegel, H.G. 1983. Biology of aerobic carbon monoxideoxidizing bacteria. Annu. Rev. Microbiol. 37: 277-310.

Mohagheghi, A., Grohmann, K., Himmel, M., Leighton, L., and Updegraff, D.M. 1986. Isolation and characterization of Acidothermus cellulolyticus gen. nov., sp. nov., a new genus of thermophilic, acidophilic, cellulolytic bacteria. Int. J. Syst. Bacteriol. 36: $435-443$.

Monteiro-Vitorello, C.B., Camargo, L.E., Van Sluys, M.A., Kitajima, J.P., Truffi, D., do Amaral, A.M., Harakava, R., de Oliveira, J.C., Wood, D., de Oliveira, M.C., et al. 2004. The genome sequence of the gram-positive sugarcane pathogen Leifsonia xyli subsp. xyli. Mol. Plant Microbe Interact. 17: 827-836.

Normand, P., Orso, S., Cournoyer, B., Jeannin, P., Chapelon, C., Dawson, J., Evtushenko, L., and Misra, A.K. 1996. Molecular phylogeny of the genus Frankia and related genera and emendation of the family Frankiaceae. Int. J. Syst. Bacteriol. 46: 1-9.

Normand, P., Lapierre, P., Tisa, L.S., Gogarten, J.P., Alloisio, N., Bagnarol, E., Bassi, C.A., Berry, A.M., Bickhart, D.M., Choisne, N., et al. 2007.
Genome characteristics of facultatively symbiotic Frankia sp. strains reflect host range and host plant biogeography. Genome Res. 17: 7-15.

Omura, S., Ikeda, H., Ishikawa, J., Hanamoto, A., Takahashi, C., Shinose, M. Takahashi, Y., Horikawa, H., Nakazawa, H., Osonoe, T., et al. 2001. Genome sequence of an industrial microorganism Streptomyces avermitilis: Deducing the ability of producing secondary metabolites. Proc. Natl. Acad. Sci. 98: 12215-12220.

Park, S.W., Hwang, E.H., Park, H., Kim, J.A., Heo, J., Lee, K.H., Song, T., Kim, E., Ro, Y.T., Kim, S.W., et al. 2003. Growth of mycobacteria on carbon monoxide and methanol. J. Bacteriol. 185: 142-147.

Rainey, F.A. and Stackebrandt, E. 1993. Phylogenetic evidence for the classification of Acidothermus cellulolyticus into the subphylum of actinomycetes. FEMS Micriobiol. Lett 108: 27-30.

Reiser, J., Muheim, A., Hardegger, M., Frank, G., and Fiechter, A. 1994. Aryl-alcohol dehydrogenase from the white-rot fungus Phanerochaete chrysosporium. Gene cloning, sequence analysis, expression, and purification of the recombinant enzyme. J. Biol. Chem. 269: 2815228159.

Rubin, E.M. 2008. Genomics of cellulosic biofuels. Nature 454: 841-845.

Sakon, J., Adney, W.S., Himmel, M.E., Thomas, S.R., and Karplus, P.A. 1996. Crystal structure of thermostable family 5 endocellulase E1 from Acidothermus cellulolyticus in complex with cellotetraose. Biochemistry 35: $10648-10660$.

Sambrook, J., Fritsch, E.F., and Maniatis, T. 1989. Molecular cloning: $A$ laboratory manual, 2nd ed. Cold Spring Harbor Laboratory Press, Cold Spring Harbor, NY.

Singer, G.A. and Hickey, D.A. 2003. Thermophilic prokaryotes have characteristic patterns of codon usage, amino acid composition and nucleotide content. Gene 317: 39-47.

Sticklen, M.B. 2008. Plant genetic engineering for biofuel production: Towards affordable cellulosic ethanol. Nat. Rev. Genet. 9: 433-443.

Suhre, K. and Claverie, J.M. 2003. Genomic correlates of hyperthermostability, an update. J. Biol. Chem. 278: 17198-17202.

Sumby, P. and Smith, M.C. 2002. Genetics of the phage growth limitation (Pgl) system of Streptomyces coelicolor A3(2). Mol. Microbiol. 44: 489-500.

Takami, H., Takaki, Y., Chee, G.J., Nishi, S., Shimamura, S., Suzuki, H., Matsui, S., and Uchiyama, I. 2004. Thermoadaptation trait revealed by the genome sequence of thermophilic Geobacillus kaustophilus. Nucleic Acids Res. 32: 6292-6303.

Thomas, S.R., Laymon, R.A., Chou, Y.C., Tucker, M.P., Vinzant, T.B., Adney, W.S., Baker, J.O., Nieves, R.A., Mielenz, J.R., and Himmel, M.E. 1995. Initial approaches to artificial cellulase systems for conversion of biomass to ethanol. In Enzymatic degradation of insoluble polysaccharides (eds. J.N. Saddler and M.H. Penner), ACS Series 618, pp. 208-236. American Chemical Society, Washington, DC.

Tucker, M.P., Mohagheghi, A., Grohmann, K., and Himmel, M.E. 1989. Ultra-thermostable cellulases from Acidothermus cellulolyticus: Comparison of temperature optima with previously reported cellulases. Biotechnology 7: 817-820.

Yakhnin, H., Pandit, P., Petty, T.J., Baker, C.S., Romeo, T., and Babitzke, P. 2007. CsrA of Bacillus subtilis regulates translation initiation of the gene encoding the flagellin protein (hag) by blocking ribosome binding. Mol. Microbiol. 64: 1605-1620.

Zeldovich, K.B., Berezovsky, I.N., and Shakhnovich, E.I. 2007. Protein and DNA sequence determinants of thermophilic adaptation. PLoS Comput. Biol. 3: e5. doi: 10.1371/journal.pcbi.0030005.

Received August 13, 2008; accepted in revised form February 24, 2009. 


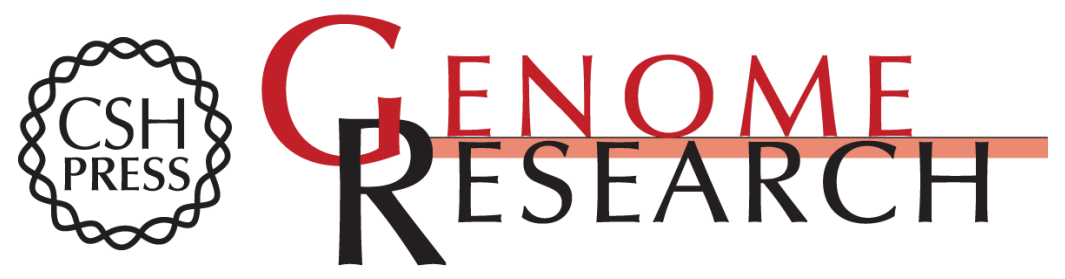

\section{Complete genome of the cellulolytic thermophile Acidothermus cellulolyticus 11B provides insights into its ecophysiological and evolutionary adaptations}

Ravi D. Barabote, Gary Xie, David H. Leu, et al.

Genome Res. 2009 19: 1033-1043 originally published online March 6, 2009

Access the most recent version at doi:10.1101/gr.084848.108

Supplemental http://genome.cshlp.org/content/suppl/2009/05/01/gr.084848.108.DC1
Material

References This article cites 41 articles, 9 of which can be accessed free at:

http://genome.cshlp.org/content/19/6/1033.full.html\#ref-list-1

License

Email Alerting Receive free email alerts when new articles cite this article - sign up in the box at the Service top right corner of the article or click here.

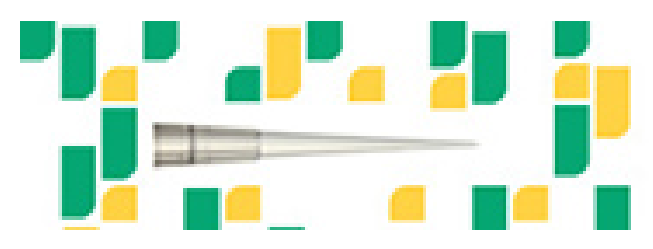

Focused on your science.

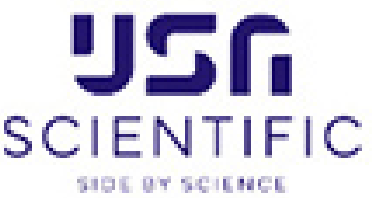

To subscribe to Genome Research go to:

https://genome.cshlp.org/subscriptions 